\title{
REVIEW
}

\section{BONE AND SOFT TISSUE CHANGES IN PATIENTS WITH SPINAL CORD INJURY AND MULTIPLE SCLEROSIS}

Yannis Dionyssiotis ${ }^{1}$, Andreas Mavrogenis ${ }^{1 *}$, Georgios Trovas ${ }^{2}$, Grigorios Skarantavos ${ }^{1}$, Jannis Papathanasiou ${ }^{3}$, Panayiotis Papagelopoulos ${ }^{1}$

${ }^{I}$ First Department of Orthopaedics, ATTIKON University Hospital, Athens University Medical School, Athens, Greece, ${ }^{2}$ Laboratory for Research of the Musculoskeletal System, KAT Hospital, Athens University Medical School, Athens, Greece, ${ }^{3}$ Department of Kinesiotherapy and Physiotherapy, Faculty of Public Health, Medical University, Sofia, Bulgaria

\section{ИЗМЕНЕНИЯ КОСТЕЙ И МЯГКИХ ТКАНЕЙ У ПАЦИЕНТОВ С ТРАВМАМИ ПО- ЗВОНКОВОГО МОЗГА И СО СОПУТСТВУЮЩИМ МНОЖЕСТВЕННЫМ СКЛЕРОЗОМ}

\author{
Янис Дионисиотис $^{1}$, Андреас Маврогенис ${ }^{1 *}$, Георгиос Тровас ${ }^{2}$, Григориос Скарантавос ${ }^{1}$, \\ Янис Папатанасиу ${ }^{3}$, Панайотис Папагелопулос ${ }^{1}$ \\ ${ }^{1}$ Первая кафедра ортопедии, Университетская больница „Атикон“", Медицинский университет, \\ Афины, Греция, 2Лаборатория исследования мышечноскелетной системы, Больница КАТ, Афины, \\ Греция, ${ }^{3}$ Сектор кинезитерапии и физиотерапии, Факультет Общественного здравоохранения, \\ Медицинский университет, София, Болгария
}

\begin{abstract}
In patients with spinal cord injury and multiple sclerosis, deterioration of body composition (changes in bone, fat and muscle mass) is associated with increased risk for diseases such as coronary artery heart disease, non-insulin dependent diabetes mellitus, lipid metabolism abnormalities, and osteoporotic fractures in these patients. Immobility leads to a changing pattern of loading in the paralyzed areas, and secondary alteration in structure. However, bone and soft tissue changes in these patients are usually neglected. The purpose of this article is to update on the pathophysiological mechanisms leading to bone and soft tissue changes, and to increase the awareness of the treating physicians with respect to bone, muscle and fat loss and their consequences aiming to obtain measures to prevent bone and soft tissue loss in these patients.
\end{abstract}

Key words: spinal cord injury, multiple sclerosis, bone, muscle and fat loss, osteoporosis

Folia Medica 2014; 56(4): 237-244

Copyright (C) 2014 Medical University, Plovdiv

\section{РЕЗЮМЕ}

У пациентов с травмами позвонкового мозга и со сопутствующим склерозом ухудшенная структура тела /изменения тела, жиры и мышечная масса/ связана с повышенным риском появления заболеваний как коронарная болезнь сердца, инсулинозависимый сахарный диабет, нарушенный метаболизм жиров, как и появление остеопоротических фрактур. Гипокинезия приводит к изменениям в моделях нагрузки парализованных областей как и к вторичным структурным изменениям. Несмотря на это обычно пациенты не обращают внимания на изменения костей и мягких тканей. Настоящая работа ставит себе целью актуализовать патофизиологические механизмы, приводящие к изменениям костных и мягких тканей, а также и повысить информированность лечащих врачей относительно костных, липидных и мышечных потерь и их последствий с целью принятия необходимых превентивных мер, чтобы уменьшить потери соответствующих тканей.

Ключевые слова: травмы позвонкового мозга, множественный склероз, кости, мылшечная илипидная (жировая) потеря, остеопороз

Folia Medica 2014; 56(4): 237-244

(C) 2014 Все права защищены. Медицинский университет, Пловдив

Article's history: Received: 3 June 2014; Received in a revised form: 7 Aug 2014; Accepted: 1 Oct 2014

*Correspondence and reprint request to: A. Mavrogenis, First Department of Orthopaedics, ATTIKON University Hospital,

Athens University Medical School, Athens; E-mail: afm@otenet.gr; Tel.: +30210-6540800

1, Rimini Str, P.C. 124 62, Haidari, Athens, Greece 


\section{INTRODUCTION}

Spinal cord injury (SCI) and multiple sclerosis (MS) change body composition because of immobilization and skeletal muscle denervation. ${ }^{1,2}$ These changes have a great implication for the health of the disabled individuals. ${ }^{3}$ Carbohydrate intolerance, insulin resistance, lipid abnormalities, bone loss and osteoporosis, and coronary artery heart disease occur prematurely and at a higher prevalence. There is a need to quantify the changes in bone, muscle and fat tissue to prevent the related diseases and their complications. ${ }^{1-3}$

The main issue with SCI and MS is that the onset of disability leads to acute (in SCI patients) or progressive (in MS patients) immobilization associated with loss of lean mass (LM) and bone mineral density (BMD) versus a gain in fat mass (FM). Both SCI and MS share different pathophysiology, location and evolution, but they may lead to similar residual immobility and reduced function for the patients. Severe MS may result in a wheelchair bound patient, which is a clinical figure equivalent to paraplegia secondary to SCI. On the contrary, patients with MS may have a more appropriate walking gait pattern compared to patients with incomplete SCI paraplegia or tetraplegia, but may also be unable to walk and be bedridden. In terms of physical disability, there are differences between complete (absence of sensory or motor function below the neurological level of the disease, including the lowest sacral segment) and incomplete lesions (partial preservation of sensory and/or motor function below the neurological level, including the lowest sacral segment). Patients with complete lesions have greater bone loss compared to those with incomplete lesions. ${ }^{3}$

Additional important differences between $\mathrm{SCI}$ and MS are the evolution of the lesion in progressive MS compared to a stable neurological status in complete paraplegia SCI, the type of injury with neurological level of injury in complete or incomplete tetraplegia or paraplegia compared to upper motor neuron pyramidal lesion in MS, and the different treatment options between the two groups of patients. Moreover, there are differences in the degree of spasticity (flaccid in MS compared to spastic paralysis in SCI patients), which is very likely to play a regulatory role in maintaining BMD. Fatigue and generalized muscle weakness in MS significantly reduces the mobility of these patients. It is more likely that body composition changes more significantly in women compared to men. ${ }^{4}$ Given that most SCIs occur before achievement of peak bone mass, and the rate of bone resorption and formation is reduced during the chronic stage of the disability, particularly below the level of injury, low values of BMD and increased risk of osteoporosis and fractures in these patients are not surprising. ${ }^{3}$

The relative difference in energy expenditure between MS patients and able-bodied individuals is probably lower than the relative difference in physical activity, because patients with MS have a higher energy expenditure of physical activity. ${ }^{5}$ Reduced physical activity and probably reduced energy expenditure in MS need to be accompanied by a reduction in energy intake otherwise body fat will increase. ${ }^{2}$ Additionally, patients with MS and SCI often experience depression that further limits mobility. ${ }^{3}$ The dependency on mobility aids and the frequent periods of immobilization after multiple operative procedures contribute to the hypoactivity status of such subjects. It could be assumed that, under these conditions, body composition may be significantly compromised in favour of fat tissue. ${ }^{6}$

The purpose of this systematic review article is to update on the pathophysiological mechanisms leading to bone and soft tissue changes, and to increase the awareness of treating physicians with respect to bone, muscle and fat loss and their consequences aiming to obtain measures to prevent bone and soft tissue loss in these patients.

\section{LITERATURE SEARCH}

We performed electronic literature search in Pubmed, Pubmed Central and Scopus databases and selected articles based on whether the title addressed the questions of interest (alterations of bone, muscle and fat in SCI and MS patients). We used as keywords "osteoporosis", "spinal cord injury", "multiple sclerosis", "body composition", "muscle mass", "fat mass", "bone loss", and "bone mineral density"; we limited the search to "English" and "German" languages, "clinical and randomized controlled trials", "observational studies", "cross-sectional diagnostic studies" and "reviews". We excluded case reports and case series without a well-designed intervention scheme or outcome measurement. The full text articles were downloaded and read. Two authors (Yannis Dionyssiotis, YD and Andreas Mavrogenis, AM) reviewed the articles to determine if they met the inclusion criteria for this systematic review. All studies employed measurements using dual-energy X-ray absorptiometry (DXA), a computed tomography (CT) or peripheral quantitative computed tomography (p QCT). Data such as study popula- 
tion, design characteristics, primary results relevant to bone loss and fractures were recorded. Citations were reviewed independently to identify additional trials that may not have been identified from the initial literature search; if there were such trials, the full-text article for any citation was also retrieved. We did not independently assess the methodological quality of the included clinical trials with the Jadad scale; this may be considered a limitation of the present systematic review. Instead, the two authors (YD and AM) analyzed the studies in order to minimize or avoid biases in the results. There was no disagreement with respect to the inclusion of articles between the authors who reviewed the articles.

ANTHROPOMETRIC MEASUREMENTS AND IMAGING FOR BODY COMPOSITION ESTIMATION IN SCI AND MS PATIENTS; WHICH METHOD FITS BEST FOR THESE POPULATIONS AND WHY?

In chronic SCI patients with paraplegia, the values of body mass index (BMI, $\mathrm{kg} / \mathrm{m}^{2}$ ) did not show statistical significance in relation to healthy controls. ${ }^{7,8}$ Other studies showed the usefulness of BMI as an indicator of obesity in patients with spinal cord injury. ${ }^{9,10}$

Body composition and distribution of fat tissue were altered in SCI patients with similar BMI; fat free mass is significantly lower in paraplegic patients in the lower extremities. In contrast, fat tissue mass is significantly higher (kilograms and $\%$ ) in the total body composition in the upper and lower extremities. ${ }^{11}$ In MS patients, BMI values are lower compared to healthy patients of same age. ${ }^{12}$ Other studies suggested an epidemic relation between obesity and MS incidence in some countries. They found that individuals with a BMI $>27$ $\mathrm{kg} / \mathrm{m}^{2}$ at age 20 years and BMI $>30 \mathrm{~kg} / \mathrm{m}^{2}$ at age 18 years are associated with a two-fold increased risk of developing MS compared to individuals with normal body weight. ${ }^{13}$

To standardize or index physiological variables, resting metabolic rate (RMR) and power $(\mathrm{P})$ fat free mass (FFM) is usually used. ${ }^{14}$ Skeletal muscle represents $50 \%$ of FFM in the total body; exact quantification of the amount of skeletal muscle is important to assess nutritional status, disease risk, danger of illnesses, physical function, atrophic effects of aging, and muscle-wasting diseases. ${ }^{15}$

Magnetic resonance imaging (MRI) and quantitative computed tomography (QCT) have been validated in human cadaver studies in the assessment of regional skeletal muscle. ${ }^{15}$ The disadvantages are the cost and radiation exposure (for QCT). During the last years, dual-energy X-ray absorptiometry (DXA) has gained acceptance as a reference method for body composition analysis. ${ }^{16}$ DXA technology offers rapid estimation of BMD, non-invasively and with minimal radiation exposure. ${ }^{14}$ DXA software determines the bone mineral and soft tissue composition in different regions of the body using a three-compartment model that quantifies the bone mineral density and bone mineral content (BMC), fat mass, and lean mass, half of which is closely correlated with muscle mass. The important issue is the investigation of distribution of bone mineral, fat and mass throughout the body since studies have found that bone density measurements at one site cannot usefully predict the bone density elsewhere because different skeletal regions, even with similar quantities of trabecular or cortical bone, may respond variably in different pathophysiological conditions. ${ }^{15}$

In patients with disability, the accuracy of skeletal muscle measured by DXA may be compromised when muscle atrophy is present. A lower ratio of muscle to fat tissue free mass indicates a lower proportion of muscle in the fat-free soft tissue mass. In SCI patients, the cross sectional area of the thigh muscles is significantly reduced. ${ }^{17}$

\section{BONE CHANGES IN SCI AND MS}

The main cause of bone changes in SCI and MS patients is not well understood; the pathophysiology is multifactorial in both acute and chronic phase. ${ }^{18,19}$ SCI always results in substantial and rapid bone loss predominately in areas below the neurological level of injury. The predominant finding in bone in SCI patients is a large loss of bone during the first year of injury and an ongoing demineralization at 3 years thereafter in the tibiae. Cancellous bone is more affected than cortical bone. In paraplegics, trabecular metaphyseal-epiphyseal areas of the distal femur and the proximal tibia are the most affected sites. Significant demineralization occurs at the distal femur $(-52 \%)$ and the proximal tibia $(-70 \%)$. Bone loss measured by DXA is similar to that in SCI patients with complete and incomplete lesions. ${ }^{18,20}$

Immobilization due to motor paralysis from central nervous system lesions contributes to loss of the normal load applied to bone in the upright position and reduced number and intensity of muscle contractions. The reduced ability to walk and stand, sitting in a wheelchair, standing on a frame or even walking with an altered gait pattern 
such as using an ankle foot orthosis result in a variable reduction of compressive forces on bone usually applied in the upright position. Moreover, since ground reaction forces are reduced, the muscle strength needed to produce movement is very low. ${ }^{21}$ The reduction of mechanical stress on bone inhibits osteoblast-mediated bone formation and accelerates osteoclast-mediated bone resorption, and leads to "disuse osteoporosis", which is evident by increased urinary calcium and reduced bone density. ${ }^{22}$ However, the high proportion of ambulatory patients with bone loss suggests that additional non-mechanical factors may be implicated. ${ }^{23}$

Mechanical unloading (paralysis) in acute SCI patients causes increased sclerostin levels and leads to reduced bone formation compared to able bodied individuals. ${ }^{24} \mathrm{~A}$ possible future walking ability (mechanical loading) during the subacute phase would modulate the response of bone to paralysis by causing a smaller increase in sclerostin levels, thereby partially protect some of the bone. In the chronic phase, sclerostin-producing osteocytes in the osteoporotic bone are less, and bone wasting results in lower sclerostin levels. Similar to the acute phase, the ability to walk partially protects against bone loss also in the chronic phase. Sclerostin causes up-regulation of receptor activator of nuclear factor kappa B ligand (RANKL) that promotes the differentiation of osteoclasts and down-regulation of osteoprotegerin expression in osteocytes, which leads to increased osteoclast activity and bone resorption. ${ }^{24}$

More evidence of the interaction between bone and immune system through molecular mechanisms exists in MS. ${ }^{25,26} \mathrm{~T}$ lymphocyte activity could stimulate bone loss under certain circumstances such as estrogen deficiency. Women with post-menopausal osteoporosis have increased $\mathrm{T}$ lymphocyte activity compared with healthy post-menopausal individuals, which could be also the case in inflammatory or autoimmune disorders such as MS: RANKL stimulates osteoclastogenesis and the same do the cytokines, such as TNF- $\alpha$, IL-1, or IL-11, all produced by $\mathrm{T}$-cells activation, leading to bone destruction. On the contrary, osteoprotegerin (OPG) is an osteoclastogenesis inhibitor that prevents the RANKL function. A balanced system of RANKL/ OPG regulates the bone metabolism. In MS this system is disturbed in favour of RANKL. ${ }^{25,26}$

Several studies suggest a strong relationship of glucocorticosteroids (GCs) with bone loss in MS. ${ }^{27}$ The mechanism is that GCs excess may cause a rapid and significant damage of bone quality by direct effect on bone, mainly to the stromalosteoblastic lineage. GCs at high concentrations alter the differentiation, survival, and function of these cells causing a shift from osteoblastic to adipocytic differentiation of precursors, inducing apoptosis of mature osteoblasts, and inhibiting the synthesis and secretion of bone components, therefore promoting osteoclasis and bone resorption. Besides GCs, immunomodulatory, antiepileptic and antidepressant drugs are also used during MS treatment. In patients receiving chronic GCs treatment per os, bone loss is rapid and is evident within 3-6 months after the beginning of treatment. ${ }^{23}$ High dose, short-term intravenous GCs treatment leads directly to reduction of bone formation and increased bone resorption, as indicated by markers of bone turnover. ${ }^{19}$ However, a study on the effect of intravenous GCs treatment in MS patients reported no clear effect on bone loss; in contrast, they reported an increase in BMD in the lumbar spine. ${ }^{28}$

This is also similar in SCI patients. In the lumbar spine, the trabecular bone demineralization remains relatively low compared to the cortical bone demineralization of long bones. Normal or even higher than normal values of BMD in the lumbar spine have been reported; this phenomenon was called "dissociated hip and spine demineralization". ${ }^{29}$ One reason for preservation of bone mass in the vertebral column is because of its continued weight-bearing function in SCI. However, several factors may affect the results of BMD measurement; these include lumbar degenerative spondylosis, bone fracture callus, vertebral fracture, calcification of the aorta, and osteosynthesis material. Yet, degenerative spondylosis is the most possible reason for false higher values of BMD. The duration of paralysis has an inverse relationship with leg and trunk percentage-matched BMD. ${ }^{18}$

The neurological level of the lesion and extent of sensory and motor impairment of function is important; tetraplegics are more likely to lose more bone mass throughout the skeleton than paraplegics..$^{30}$ Additionally, it has been reported that in paraplegics with higher neurological levels of injury, bone mineral content in the legs was more reduced and strongly negatively correlated with the duration of paralysis; this also highlights the fact that the neurological level of injury determines the extent of bone loss even among paraplegics with various neurological levels of injury. ${ }^{31} \mathrm{~A}$ similar severity of demineralization in the sublesional area was shown between paraplegics and tetraplegics. ${ }^{30}$ Low testosterone values in SCI and MS patients 
do not explain bone loss and no clear effect of smoking or alcohol abuse to decreased bone mass could be established. ${ }^{3}$

It still remains controversial whether or not bone remodelling is re-established after SCI; some authors reported that approximately 2 years after SCI, a new steady status between bone resorption and formation would be re-established, whereas others found that there was no sign of a new steady status in bone formation in the lower extremities at the same time period after the SCI. The effect of aging on bone in complete SCI patients is also unclear; some authors reported moderate correlation between age and reduced femoral BMD in acute SCI, while others reported no relation with age of reduced BMD and bone mineral content in identical male twins with SCI. ${ }^{18}$

Inconsistent results have also been reported regarding the effect of muscle spasms on BMD in SCI patients. ${ }^{32-34}$ Muscle spasms and muscle tension put forces on bone and may likely play a regulatory role in maintaining bone density. In contrast, excessive spasticity may cause fractures through uncontrolled limb movements. Therefore, probably, spasticity may be protective against bone loss in SCI patients ${ }^{33}$; yet, low grade spasticity benefits bones and high grade harms. Patients with spasticity were found to have higher BMD compared with those with flaccid paralysis. ${ }^{33}$

\section{MUSCLE CHANGES IN SCI AND MS}

Soon after SCI, muscle fibers begin to change their functional properties. Muscle cross-sectional area (CSA) declines from 1 to 17 months after injury and thereafter reaches nadir. Conversion to type II fibers has been suggested to occur between 4 months and 2 years after SCI, resulting in even slowtwitch muscle becoming predominantly fast twitch thereafter. Small fibers, predominantly fast-twitch muscle and reduced mitochondrial content have been reported years after injury in cross-sectional studies. These data have been interpreted to suggest that human skeletal muscle shows plasticity. ${ }^{17}$

Muscle atrophy in SCI is of central type and depends on the disuse and loss of upper connections of the lower motor neurons, sometimes associated with the loss of anterior horn cells and transsynaptic degeneration. The latter change may be responsible for the denervation changes seen in early stages after SCI. In late stages, 10-17 months after SCI, diffuse muscle atrophy with reduction of muscle fascicles dimension associated with fat infiltration and endomysial fibrosis occurs. In any stage after
SCI, almost all patients show myopathic changes such as internal nuclei, fibres degeneration and cytoplasmic vacuolation due to lipid accumulation. Spasticity and microvascular damage contribute to the induction of marked morphological and enzyme histochemical changes seen in the paralyzed skeletal muscles. ${ }^{35}$ However, these changes may not apply for upper extremity muscles in paraplegic patients. Another reason for skeletal muscle changes is prolonged GCs treatment that causes catabolism and atrophy of skeletal muscle because of decreased amino acid transport into muscle and increased glutamine synthesis activity. Endogenous GCs excess also produces generalized osteoporosis that is most prevalent in trabecular-rich bones. Studies also reported that muscle mass of the contralateral limb was lower than that in the ipsilateral limb in upper motor neuron lesions. Similar findings have also been reported in patients with incomplete SCI. ${ }^{3}$ There is a high incidence of vitamin D deficiency $(<20 \mathrm{ng} / \mathrm{ml})$ in SCI and MS patients. ${ }^{36,37}$ This may be explained by a combination of low dietary vitamin D intake and low sun exposure (mainly in MS patients to avoid worsening of symptoms). However, there is no strong evidence to support supplementation because of lack of double-blind randomized placebo-controlled studies. Neuromuscular functional electrical stimulation (FES) that directly stimulates peripheral nerves to cause muscle contractions for muscle conditioning and functional motor output has been used to strengthen muscles that are weakened by neurological damage. ${ }^{38}$

A significant inverse relation between free fat mass and Expanded Disability Status Scale (EDSS) score was reported between ambulatory and nonambulatory MS patients. It would seem apparent that ambulatory patients with MS and healthy controls would strengthen the inverse relation between FFM and EDSS score. ${ }^{2}$

\section{FAT CHANGES IN SCI AND MS}

Studies in SCI patients found an association of the duration of paralysis with parameters below and above the neurological level of injury (upper extremities fat mass), which raises the question of the existence of a hormonal mechanism as a regulator in paraplegics' body composition. ${ }^{31}$ The hormone leptin is secreted by fat cells and regulates body weight and energy consumption. ${ }^{39}$ In paraplegics, when compared with healthy subjects, higher levels of leptin have been found, possibly due to greater fat tissue storage. ${ }^{64}$ Leptin activates the sympathetic nervous system (SNS) through a 
central administration. The disruption of the sympathetic nervous system may modify the secretion and activity of the leptin, because the sympathetic preganglionic neurons become atrophic in high level paraplegics. ${ }^{18}$ The thoracic level 6 (T6) appears to be the lowest level of injury in most patients with SCI to develop autonomic dysreflexia. SCI above T6 level is associated with reduced SNS outflow and supraspinal control to the splanchnic outflow and lower-extremity blood vessels. Multiple regression analysis showed that serum leptin levels in men with SCI correlated not only with BMI but also with the neurologic deficit. This finding supports the notion that decentralization of sympathetic nervous activity relieves its inhibitory tone on leptin secretion, because subjects with tetraplegia have a more severe deficit of sympathetic nervous activity. ${ }^{3,18}$

Given that in high level paraplegia, disorder of the autonomic nervous system occurs and leptin activates the sympathetic nervous system through central control, it was formulated that the "closure" of central nervous system pathways disrupts the effect of leptin and possibly increases the risk of obesity in high level SCI patients. ${ }^{3,18}$

No significant difference in body fat composition was observed between ambulatory MS patients and healthy controls despite the lower physical activity of the former. ${ }^{2}$ Additionally, in MS patients no significant relation was observed with respect to any of the body composition measures and the level of disability as measured by the Expanded Disability Status Scale (EDSS). A possible explanation for the similar body composition may be the lower energy intake in ambulatory MS patients and the higher energy cost during physical activity (walking) in MS patients compared to healthy controls. ${ }^{2}$

The level of disability of ambulatory MS patients does not predict body composition; no significant differences were observed between EDSS score and body fat percent, nor between physical activity and the level of disability. This finding suggests that a higher level of disability does not force these individuals to be physically inactive and does not result in a greater body fat content. ${ }^{6,40}$

\section{AUTHORS' COMMENTARY}

Patients with SCI and MS face serious alterations of body composition (Table 1). The potential risks involved with these changes, i.e. loss of lean tissue mass and bone mineral density, compared to gain in fat mass in body composition have implications for the health of disabled individuals. Body fat has been identified as a significant predictor of mortality in humans making body composition measurement to quantify nutritional and health status an important issue for human health. Moreover, some disorders such as carbohydrate intolerance, insulin resistance, lipid abnormalities and heart disease occur prematurely and at a higher prevalence in disabled populations, and may be related to adverse changes in body composition that result from immobilization and skeletal muscle denervation. While in SCI the problem starts immediately after injury, in MS it is mostly progressive. After the acute immobilization

Table 1. Key points of bone and soft tissue changes in SCI and MS patients

Healthy BMI values often underestimate body fat and may mask adiposity in SCI.

Spasticity does not defend skeletal muscle mass and bone. Probably, after SCI, the myopathic muscle cannot recognize correctly the stimulation because of the neurogenic injury.

The marked atrophy of paralyzed muscles after SCI suggests a preferential atrophic response in the antigravity muscles.

$\mathrm{SCI}$ induces a decline in BMD, BMC and the geometric characteristics of bone in the paralyzed segments.

There is a high incidence of vitamin D deficiency in MS and SCI patients.

The relationship between skeletal muscle and impaired motor function in MS remains unclear.

The deterioration of body composition is usually neglected and increases the risk for coronary artery heart disease, non-insulin dependent diabetes mellitus, lipid abnormalities, bone loss and osteoporotic fractures.

Bone loss, unlike muscle atrophy, is essentially irreversible once established in SCI and MS patients.

Focused physical medicine and rehabilitation therapies on how to bear weight and stand, and therapeutic walking activities early in the post injury period are necessary in SCI and MS patients to prevent bone, muscle and fat changes. 
period, the patients with SCI perform standing using tilt-tables, long leg braces and standing frames in the hospital. Standing is often continued at home after discharge from the hospital. The main reason for not performing standing is mostly the unwillingness of the patient, rather than the functional level. It is well known that after SCI onset rehabilitation efforts are very strong but patients lose their faith and motivation during aging in paralysis. This means that they do not follow the suggestions from the physicians and do not perform among other things standing or walking with leg braces orthoses. Similarly with SCI, the patients with MS lose quickly their motivation. During the day they spend lots of time in the wheelchair or prefer to be bedridden because they are facing the problem of depression also.

\section{CONCLUSIONS}

In SCI and MS patients with disability, the most important issue of body composition is to achieve optimal body weight aiming to reduce the risk of coronary artery heart disease, non-insulin dependent diabetes mellitus, lipid abnormalities and fractures because of bone loss. Dietary changes with lower energy intake, individualized physical activity programs and medications should be included in the therapy of these patients. Physicians should be aware that BMI values often underestimate body muscle and fat and may mask adiposity, and spasticity does not defend skeletal muscle mass and bone. Moreover, patients with disabilities usually transfer most of their body weight during daily activities on their upper extremities reducing the weight-bearing of the affected lower extremity muscles, which triggers a cycle of added muscle atrophy, finally establishing an irreversible decline in $\mathrm{BMD}, \mathrm{BMC}$ and geometric characteristics of bone. Current approach to these patients should aim at focused physical medicine and rehabilitation therapies on how to bear weight and stand, and therapeutic walking activities early in the post injury period to prevent bone, muscle and fat changes in SCI and MS patients.

\section{REFERENCES}

1. Spungen AM, Adkins RH, Stewart CA, et al. Factors influencing body composition in persons with spinal cord injury: a cross-sectional study. J Appl Physiol 2003;95:2398-407.

2. Lambert CP, Archer RL, Evans WJ. Body composition in ambulatory women with multiple sclerosis. Arch Phys Med Rehabil 2002;83:1559-61.
3. Dionyssiotis Y. Body Composition in Disabilities of Central Nervous System. In: El Maghraoui A, editor. Dual Energy X-Ray Absorptiometry. Rijeka: InTech; 2012:75-94.

4. Smeltzer SC, Zimmerman V, Capriotti T. Osteoporosis risk and low bone mineral density in women with physical disabilities. Arch Phys Med Rehabil 2005;86:582-6.

5. Olgiati R, Burgunder JM, Mumenthaler M. Increased energy cost of walking in multiple sclerosis: effect of spasticity, ataxia, and weakness. Arch Phys Med Rehabil 1988;69:846-9.

6. Dionyssiotis Y. Body composition in multiple sclerosis. Hippokratia 2013;17:7-11.

7. Dionyssiotis Y, Petropoulou K, Rapidi CA, et al. Body composition in paraplegic men. J Clin Densitometry 2008;11:437-43.

8. Maggioni M, Bertoli S, Margonato V, Merati G, Veicsteinas A, Testolin G. Body composition assessment in spinal cord injury subjects. Acta Diabetol 2003;40 Suppl 1:S183-6.

9. Gupta N, White KT, Sandford PR. Body mass index in spinal cord injury - a retrospective study. Spinal Cord 2006;44:92-4.

10. McDonald CM, Abresch-Meyer AL, Nelson MD, Widman LM. Body mass index and body composition measures by dual x-ray absorptiometry in patients aged 10 to 21 years with spinal cord injury. J Spinal Cord Med 2007;30:S97-104.

11. Maimoun L, Fattal C, Micallef JP, Peruchon E, Rabischong P. Bone loss in spinal cord-injured patients: from physiopathology to therapy. Spinal Cord 2006;44:203-10.

12. Sioka C, Fotopoulos A, Georgiou A, et al. Body composition in ambulatory patients with multiple sclerosis. J Clin Densitom 2011;14:465-70.

13. Munger KL, Chitnis T, Ascherio A. Body size and risk of MS in two cohorts of US women. Neurology 2009;10:1543-50.

14. Van Der Ploeg GE, Withers RT, Laforgia J. Percent body fat via DEXA: comparison with a four-compartment model. J Appl Physiol 2003;94:499-506.

15. Modlesky CM, Bickel CS, Slade JM, Meyer RA, Cureton KJ, Dudley GA. Assessment of skeletal muscle mass in men with spinal cord injury using dual-energy X-ray absorptiometry and magnetic resonance imaging. J Appl Physiol 2004;96:561-5.

16.LaForgia J, Dollman J, Dale MJ, Withers RT, Hill AM. Validation of DXA body composition estimates in obese men and women. Obesity (Silver Spring) 2009;17:821-6.

17. Castro MJ, Apple DF Jr, Hillegass EA, Dudley GA. Influence of complete spinal cord injury on skeletal muscle cross-sectional area within the first 6 months of injury. Eur J Appl Physiol 1999;80:373-8. 
18. Dionyssiotis Y. Spinal cord injury-related bone impairment and fractures: an update on epidemiology and physiopathological mechanisms. J Musculoskelet Neuronal Interact 2011;11:257-65.

19.Dionyssiotis Y. Bone loss and fractures in multiple sclerosis: focus on epidemiologic and physiopathological features. Int J Gen Med 2011;4:505-9.

20. Jiang SD, Dai LY, Jiang LS. Osteoporosis after spinal cord injury. Osteoporos Int 2006;17:180-92.

21. Bloomfield SA. Changes in musculoskeletal structure and function with prolonged bed rest. Med Sci Sports Exerc 1997;29:197-206.

22. Takata S, Yasui N. Disuse osteoporosis. J Med Invest 2001;48:147-56.

23. Cosman F, Nieves J, Komar L, et al. Fracture history and bone loss in patients with MS. Neurology 1998;51:1161-5.

24. Morse LR, Sudhakar S, Danilack V, et al. Association between sclerostin and bone density in chronic spinal cord injury. J Bone Miner Res 2012;27:352-9.

25.Zhao W, Liu Y, Cahill CM, et al. The role of T cells in osteoporosis, an update. Int J Clin Exp Pathol 2009;20:544-52.

26. Kurban S, Akpinar Z, Mehmetoglu I. Receptor activator of nuclear factor kappa B ligand (RANKL) and osteoprotegerin levels in multiple sclerosis. Mult Scler 2008; 14:431-2.

27. Canalis E, Mazziotti G, Giustina A, et al. Glucocorticoid-induced osteoporosis: pathophysiology and therapy. Osteoporos Int 2007;18:1319-28.

28.Zorzon M, Zivadinov R, Locatelli L, et al. Long-term effects of intravenous high dose methylprednisolone pulses on bone mineral density in patients with multiple sclerosis. Eur J Neurol 2005;12:550-6.

29.Leslie WD, Nance PW. Dissociated hip and spine demineralization: a specific finding in spinal cord injury. Arch Phys Med Rehabil 1993;74:960-4.

30. Tsuzuku S, Ikegami Y, Yabe K. Bone mineral density differences between paraplegic and quadriple- gic patients: a cross-sectional study. Spinal Cord 1999;37:358-61.

31.Dionyssiotis Y, Lyritis GP, Papaioannou N, Papagelopoulos $\mathrm{P}$, Thomaides T. Influence of neurological level of injury in bones, muscles, and fat in paraplegia. J Rehabil Res Dev 2009;46:1037-44.

32. Dionyssiotis Y, Lyritis GP, Mavrogenis AF, Papagelopoulos PJ. Factors influencing bone loss in paraplegia. Hippokratia 2011;15:54-9.

33. Eser P, Frotzler A, Zehnder Y, Schiess1 H, Denoth J. Assessment of anthropometric, systemic, and lifestyle factors influencing bone status in the legs of spinal cord injured individuals. Osteoporos Int 2005;16:26-34.

34.Löfvenmark I, Werhagen L, Norrbrink C. Spasticity and bone density after a spinal cord injury. J Rehabil Med 2009;41:1080-4.

35. Scelsi R. Skeletal muscle pathology after spinal cord injury. Basic Appl Myol 2001;11:75-85.

36. Bauman WA, Zhong YG, Schwartz E. Vitamin D deficiency in veterans with chronic spinal cord injury. Metabolism 1995;44:1612-6.

37. Van Amerongen BM, Dijkstra CD, Lips P, et al. Multiple sclerosis and vitamin D: an update. Eur J Clin Nutr 2004;58:1095-109.

38. Askari S, Chao T, de Leon RD, Won DS. The effect of timing electrical stimulation to robotic-assisted stepping on neuromuscular activity and associated kinematics. J Rehabil Res Dev 2013;50:875-92.

39. Jeon JY, Steadward RD, Wheeler GD, Bell G, McCargar L, Harber V. Intact sympathetic nervous system is required for leptin effects on resting metabolic rate in people with spinal cord injury. J Clin Endocrinol Metab 2003;88:402-7.

40. Formica CA, Cosman F, Nieves J, Herbert J, Lindsay R. Reduced bone mass and fat-free mass in women with multiple sclerosis: effects of ambulatory status and glucocorticoid Use. Calcif Tissue Int 1997;61:129-33. 